\title{
Modeling of One-Dimensional Smoldering of Polyurethane in Microgravity Conditions
}

\author{
Guillermo Rein ${ }^{1}$, Amnon Bar-Ilan ${ }^{1}$, A. Carlos Fernandez-Pello ${ }^{1 *}$, \\ Janet L. Ellzey ${ }^{2}$, Jose L. Torero ${ }^{3}$, David L. Urban ${ }^{4}$ \\ ${ }^{1}$ University of California at Berkeley, Berkeley, CA 94720, USA \\ ${ }^{2}$ University of Texas at Austin, Austin, TX 78712, USA \\ ${ }^{3}$ University of Edinburgh, Edinburgh EH93JN, UK, \\ ${ }^{4}$ NASA Glenn Research Center, Cleveland, OH 44135, USA
}

\begin{abstract}
Results are presented from a model of forward smoldering combustion of polyurethane foam in microgravity. The transient one-dimensional numerical-model is based on that developed at the University of Texas at Austin. The conservation equations of energy, species and mass in the porous solid and in the gas phases are numerically solved. The solid and the gas phase are not assumed to be in thermal or in chemical equilibrium. The chemical reactions modeled consist of foam oxidation and pyrolysis reactions, as well as char oxidation. The model has been modified to account for new polyurethane kinetics parameters and radial heat losses to the surrounding environment. The kinetics parameters are extracted from thermogravimetric analyses published in the literature and using Genetic Algorithms as the optimization technique. The model results are compared with previous tests of forward smoldering combustion in microgravity conducted aboard the NASA Space Shuttle. The model calculates well the propagation velocities and the overall smoldering characteristics. Direct comparison of the solution with the experimental temperature profiles shows that the model predicts well these profiles at high temperature, but not as well at lower temperatures. The effect of inlet gas velocity is examined and the minimum airflow for ignition identified. It is remarkable that this one-dimensional model with simplified kinetics is capable of predicting cases of smolder ignition but with no self-propagation away from the igniter region. The model is used for better understanding of the controlling mechanisms of smolder combustion for the purpose of fire safety, both in microgravity and normal gravity, and to extend the unique microgravity data to wider conditions avoiding the high cost of space-based experiments.
\end{abstract}

Keywords: Smoldering; Numerical Model; Microgravity; Polyurethane; Kinetics

$\begin{array}{ll}\text { Nomenclature } \\ A_{i} & \text { Preexponential factor of reaction rate } i \\ A_{L} / V & \text { Lateral area to volume ratio } \\ A_{g s} / V & \text { Gas solid surface to volume ratio } \\ c & \text { Specific heat } \\ E_{i} & \text { Activation energy of reaction } i \\ h_{g s} & \text { Gas/solid heat transfer coefficient } \\ h_{m} & \text { Gas/solid mass transfer coefficient } \\ k & \text { Thermal conductivity } \\ L & \text { Sample length } \\ T & \text { Temperature }\end{array}$

$\begin{array}{ll}u & \text { Velocity } \\ U_{e} & \text { Heat-transfer coefficient to exteroir } \\ V_{i} & \text { Diffusional velocity of species } i \\ W_{i} & \text { Weight of solid species } i \\ W_{0} & \text { Weight of the original foam } \\ y & \text { Mass fraction } \\ \text { Greek symbols } \\ \Delta h \quad \text { Heat of reaction } \\ \phi & \text { Porosity of the foam } \\ v & \text { Mass stoichiometric coefficient } \\ \rho & \text { Density } \\ \omega & \text { Reaction rate }\end{array}$




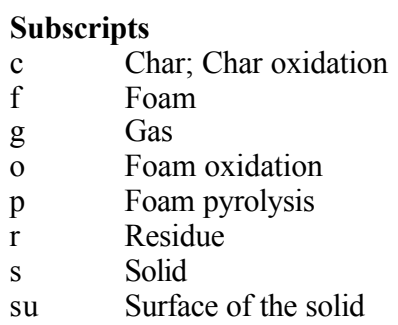

\section{Introduction}

Smoldering is a surface combustion wave that propagates through a porous fuel matrix [1], and involves complex processes related to fluid flow, heat transfer and heterogeneous chemical reactions in porous media. In smolder, the combustion process is generally oxygen deficient, and the propagating reaction leaves behind a char that contains a significant amount of unburned fuel. The heat released by smoldering is low compared to flaming combustion, and its propagation is a slow process. Heat losses and oxygen availability are the most important parameters controlling smolder propagation. One-dimensional smolder is classified in two different modes of propagation, forward and opposed. In forward smolder, the reaction front while in opposed smolder the front moves in the opposite direction relative to the oxidizer.

In spite of its weakly reacting characteristics, smoldering combustion has significant importance in fire safety because its combustion by-products are toxic, it is difficult to detect and can suddenly transition to flaming. Smolder of cable insulation is of particular importance in the space program; to date there have been a few minor incidents of overheated and charred cables and electrical components reported on Space Shuttle flights [3]. Other smolder-related issues of concern to fire safety occurred aboard Russian spacecrafts [4]. The establishment of the International Space Station and other planned remote-facilities has increased interest in smoldering in microgravity because of the need to minimize the effect of a smolder-initiated fire.

Numerical simulations of smoldering combustion are used for better understanding of the controlling mechanisms of smolder for the purpose of fire-safety control and prevention. Results from various moves in the same direction as the oxidizer flow,

numerical models of smolder are reported in the literature $[5,6,7]$.

Space-based experiments are unique because of their high cost and consequently it is of great importance to use models to extend the limited microgravity data to wider conditions, fuels and configurations.

In this study, results are presented from a onedimensional transient numerical-simulation of forward smoldering in microgravity. The results of the model are calibrated and then compared to the microgravity data. These microgravity experiments were conducted aboard the NASA Space Shuttle missions STS-105 and STS-108 [8].

\section{Numerical Model}

The computational model used here is based on that developed by Leach et al. [7]. It solves the onedimensional time-dependent conservation equations for the solid and the gas. Following the forward configuration, air is forced and ignition is initiated at the right boundary (Fig. 1). As a result the reaction front propagates from right to left.

Details of the computational model are published elsewhere [7] and here an overview is given in addition to the modifications. The conservation equations solved are; solid species Eqs. (1)-(3), solid energy Eq. (4), gas-phase energy Eq. (5), gas-phase continuity Eq. (6), oxygen in the bulk gas Eq. (7) and oxygen at the surface Eq. (8). Heat transfer inside the porous solid by radiation is included into the conductivity assuming the optically thick limit. Convection from the solid to the gas, and heat losses to the surrounding environment are also included. Oxygen transport from the solid surface to the bulk gas is taken into account. Buoyant-induced flows are not modeled, so the simulations are in microgravity conditions. Solid properties are weight averaged for the solid species considered; foam, char and residue

$$
\begin{aligned}
& \frac{\partial}{\partial \mathrm{t}}\left(\frac{\mathrm{W}_{\mathrm{f}}}{\mathrm{W}_{0}}\right)=-\omega_{\mathrm{p}}-\omega_{\mathrm{o}} \\
& \frac{\partial}{\partial \mathrm{t}}\left(\frac{\mathrm{W}_{\mathrm{c}}}{\mathrm{W}_{0}}\right)=\mathrm{v}_{\mathrm{c}, \mathrm{p}} \omega_{\mathrm{p}}+\mathrm{v}_{\mathrm{c}, \mathrm{o}} \omega_{\mathrm{o}}-\omega_{\mathrm{c}} \\
& \frac{\partial}{\partial \mathrm{t}}\left(\frac{\mathrm{W}_{\mathrm{r}}}{\mathrm{W}_{0}}\right)=\mathrm{v}_{\mathrm{r}, \mathrm{c}} \omega_{\mathrm{c}}
\end{aligned}
$$

$\rho_{\mathrm{s}} \mathrm{c}_{\mathrm{s}} \frac{\partial \mathrm{T}_{\mathrm{s}}}{\partial \mathrm{t}}=\frac{\partial}{\partial \mathrm{x}}\left(\mathrm{k}_{\mathrm{s}} \frac{\partial \mathrm{T}_{\mathrm{s}}}{\partial \mathrm{x}}\right)-\omega_{\mathrm{o}} \rho_{\mathrm{f}} \Delta \mathrm{h}_{\mathrm{o}}-\omega_{\mathrm{p}} \rho_{\mathrm{f}} \Delta \mathrm{h}_{\mathrm{p}}-\omega_{\mathrm{c}} \rho_{\mathrm{c}} \Delta \mathrm{h}_{\mathrm{c}}+\frac{\mathrm{h}_{\mathrm{gg}} \mathrm{A}_{\mathrm{gg}}}{\mathrm{V}}\left(\mathrm{T}_{\mathrm{g}}-\mathrm{T}_{\mathrm{s}}\right)+\frac{\mathrm{U}_{\mathrm{e}} \mathrm{A}_{\mathrm{L}}}{\mathrm{V}}\left(\mathrm{T}_{0}-\mathrm{T}_{\mathrm{s}}\right)$

$\phi \rho_{\mathrm{g}} \mathrm{c}_{\mathrm{pg}}\left(\frac{\partial \mathrm{T}_{\mathrm{g}}}{\partial \mathrm{t}}+\mathrm{u} \frac{\partial \mathrm{T}_{\mathrm{g}}}{\partial \mathrm{x}}\right)=\phi \mathrm{k}_{\mathrm{g}} \frac{\partial^{2} \mathrm{~T}_{\mathrm{g}}}{\partial \mathrm{x}^{2}}+\frac{\mathrm{h}_{\mathrm{gs}} \mathrm{A}_{\mathrm{gs}}}{\mathrm{V}}\left(\mathrm{T}_{\mathrm{s}}-\mathrm{T}_{\mathrm{g}}\right)$

$\frac{\partial}{\partial t}\left(\rho_{g} \phi\right)+\frac{\partial}{\partial x}\left(\rho_{g} \phi u\right)=\phi\left[\omega_{p} \rho_{f} v_{g, p}+\omega_{o} \rho_{f}\left(v_{g_{1} 0}-v_{O 2, o}\right)+\omega_{c} \rho_{c}\left(v_{g, c}-v_{O 2, c}\right)\right]$ 


$$
\begin{aligned}
& \frac{\partial}{\partial \mathrm{t}}\left(\rho_{\mathrm{g}} \phi \mathrm{y}_{\mathrm{O} 2}\right)_{\mathrm{b}}+\frac{\partial}{\partial \mathrm{x}}\left(\rho_{\mathrm{g}} \phi \mathrm{uy}_{\mathrm{O} 2}\right)_{\mathrm{b}}+\frac{\partial}{\partial \mathrm{x}}\left(\rho_{\mathrm{g}} \phi \mathrm{y}_{\mathrm{O} 2} \mathrm{~V}_{\mathrm{O} 2}\right)_{\mathrm{b}}=-\frac{\mathrm{h}_{\mathrm{m}} \mathrm{A}_{\mathrm{gs}}}{\mathrm{V}}\left(\mathrm{y}_{\mathrm{O} 2}-\mathrm{y}_{\mathrm{O} 2, \mathrm{su}}\right) \\
& \frac{\partial}{\partial \mathrm{t}}\left(\rho_{\mathrm{g}} \phi \mathrm{y}_{\mathrm{O} 2}\right)_{\mathrm{su}}+\frac{\partial}{\partial \mathrm{x}}\left(\rho_{\mathrm{g}} \phi \mathrm{y}_{\mathrm{O} 2} \mathrm{~V}_{\mathrm{O} 2}\right)_{\mathrm{su}}=-\omega_{\mathrm{o}} \rho_{\mathrm{f}} \mathrm{v}_{\mathrm{O} 2, \mathrm{o}}-\omega_{\mathrm{c}} \rho_{\mathrm{c}} \mathrm{v}_{\mathrm{O} 2, \mathrm{c}}+\frac{\mathrm{h}_{\mathrm{m}} \mathrm{A}_{\mathrm{gg}}}{\mathrm{V}}\left(\mathrm{y}_{\mathrm{O} 2}-\mathrm{y}_{\mathrm{O} 2, \mathrm{su}}\right)
\end{aligned}
$$

A three-step chemical-reaction scheme for polyurethane foam [1] with its corresponding Arrhenius-type reaction rates, Eqs. (9)-(11), were implemented into the model.

$$
\text { Endothermic foam pyrolysis: }
$$$$
\text { 1g Foam } \rightarrow v_{c, p} \text { Char }+v_{g, p} \text { Gas }
$$$$
\omega_{\mathrm{p}}=\mathrm{A}_{\mathrm{p}} \mathrm{e}^{-\frac{\mathrm{E}_{\mathrm{ap}}}{\mathrm{RT}_{\mathrm{s}}}}\left(\frac{\mathrm{W}_{\mathrm{f}}}{\mathrm{W}_{0}}\right)^{\mathrm{n}_{\mathrm{p}}}
$$

Exothermic foam

$$
\begin{aligned}
& \text { 1g Foam }+v_{\mathrm{O} 2, \mathrm{o}} \mathrm{O}_{2} \rightarrow v_{\mathrm{c}, \mathrm{o}} \text { Char }+v_{\mathrm{g}, \mathrm{o}} \text { Gas } \\
& \omega_{\mathrm{o}}=\mathrm{A}_{\mathrm{o}} \mathrm{e}^{-\frac{\mathrm{E}_{\mathrm{a}}}{\mathrm{RT_{ \textrm {s } }}}} \frac{\mathrm{W}_{\mathrm{f}}}{\mathrm{W}_{0}} \mathrm{y}_{\mathrm{O} 2}
\end{aligned}
$$

Exothermic char oxidation:

$$
\begin{aligned}
& \text { 1g Char }+v_{\mathrm{O} 2, \mathrm{c}} \mathrm{O}_{2} \rightarrow v_{\mathrm{r}, \mathrm{c}} \text { Residue }+v_{\mathrm{g}, \mathrm{c}} \text { Gas } \\
& \omega_{\mathrm{c}}=\mathrm{A}_{\mathrm{c}} \mathrm{e}^{-\frac{\mathrm{E}_{\mathrm{ac}}}{\mathrm{RT}_{\mathrm{s}}}} \frac{\mathrm{W}_{\mathrm{c}}}{\mathrm{W}_{0}} \mathrm{y}_{\mathrm{O} 2}
\end{aligned}
$$

Boundary conditions are implemented so that at $t=0$, the entire fuel bed is unreacted and the temperature of solid and gas is $27^{\circ} \mathrm{C}$. The ignition of the sample occurs at the right boundary $(x=L)$ by applying a constant heat flux and a low airflow $(0.01 \mathrm{~mm} / \mathrm{s})$ for $400 \mathrm{~s}$. After the ignition, the airflow is set to the nominal value and kept constant and heat is lost to the surrounding. These boundary conditions imitate the ignition protocol used in the microgravity experiments of [8]. Inlet gas temperature and composition are kept constant at the right boundary $x=L$. At the left boundary $(x=0)$, the by-product gases exit and there is a zero gradient for composition and heat is lost to the surrounding. The equations are discretized in the space domain and solved with time using the stiff integrator VODE [9]. The original computer code [7] did not model the heat losses to the surrounding environment, used the kinetics of cellulose and was calibrated with normal gravity experiments. To improve the model, in this study we have included radial heat losses and new kinetics for polyurethane, and microgravity experiments are used for calibration and comparison. The heat-loss coefficient to the surrounding environment is analytically calculated elsewhere [2] $\left(U_{e}=0.3 \mathrm{~W} / \mathrm{m}^{2}\right)$ for the particular experimental setup in [8] and applied to Eq. (4).

\subsection{Polyurethane Chemical Kinetics}

In order to better model the polyurethane smoldering experiments of Bar-Ilan et al. [8] a new set of kinetics parameters for the polyurethane reaction rates (Eqs. (9)-(11)) have been extracted.

This kinetics for flexible polyurethane foam are based on the thermogravimetric analyses published by Chao and Wang [10]. Following the three-step mechanism indicated above, the kinetics parameters that best fit the thermogravimetric experiments have been derived. The method consists of the numerical integration of the solid weight time-change, Eqs. (12) and (13), in conditions similar to those encountered during a thermogravimetric analysis, Eq. (14), and compare to experiments. The optimization of these 10 parameters has been conducted using genetic algorithms [11].

$\frac{\mathrm{d}}{\mathrm{dt}}\left(\frac{\mathrm{W}}{\mathrm{W}_{0}}\right)=\frac{\mathrm{d}}{\mathrm{dt}}\left(\frac{\mathrm{W}_{\mathrm{f}}}{\mathrm{W}_{0}}\right)+\frac{\mathrm{d}}{\mathrm{dt}}\left(\frac{\mathrm{W}_{\mathrm{c}}}{\mathrm{W}_{0}}\right)+\frac{\mathrm{d}}{\mathrm{dt}}\left(\frac{\mathrm{W}_{\mathrm{r}}}{\mathrm{W}_{0}}\right)$

$=\left(v_{c, p}-1\right) \omega_{p}+\left(v_{c, o}-1\right) \omega_{o}+\left(v_{r, c}-1\right) \omega_{c}$

$\frac{\mathrm{dT}_{\mathrm{s}}}{\mathrm{dt}}=$ constant

Conditions $\left\{\begin{array}{l}\mathrm{W} / \mathrm{W}_{0}=1 \text { for } \mathrm{t}=0 \\ \mathrm{y}_{\mathrm{O} 2}=0 \text { (inert atm.) } \\ \text { or } \mathrm{y}_{\mathrm{O} 2}=0.23 \text { (air atm.) }\end{array}\right.$

The thermogravimetric experiment in inert $(100 \%$ $\mathrm{N}_{2}$ ) atmosphere is used to study the pyrolysis of the foam and in the air atmosphere to study the foam and char oxidations. Thermogravimetric experiments at a heating rate of $10^{\circ} \mathrm{C} / \mathrm{min}$ for the inert atmosphere show two consecutive reaction-paths (Fig. 2); the first reaction takes places between $230^{\circ} \mathrm{C}$ and $320^{\circ} \mathrm{C}$, while the second does between $320^{\circ} \mathrm{C}$ and $410^{\circ} \mathrm{C}$. Since the smolder model considers only one pyrolysis reaction, its kinetics parameters are set as a compromise solution between both reaction paths to approximate the thermogravimetric behavior in $\mathrm{N}_{2}$.

For air, the thermogravimetric results at the same heating rate (Fig. 2) show three consecutive reaction-paths; the degradation of the foam (the output of the competitive reactions of oxidation and pyrolysis) taking place between $230^{\circ} \mathrm{C}$ and $340^{\circ} \mathrm{C}$, the consecutive char oxidation taking place between $340^{\circ} \mathrm{C}$ and $420^{\circ} \mathrm{C}$, and the last reaction is the further char oxidation to secondary char, taking place between $420^{\circ} \mathrm{C}$ and $570^{\circ} \mathrm{C}$. The temperature ranges for the reactions depend on the heating rate and this discussion refers to a heating rate of $10^{\circ} \mathrm{C} / \mathrm{min}$. Of the three reactions, only the first two are implemented in our computational model, since the char oxidation to secondary char has been identified as having little importance in smolder propagation [12]. Since the pyrolysis kinetics values were 
derived from thermogravimetric data in inert gas, the air data can be used to determine the remaining kinetics values for the foam and char oxidations. Integration of Eqs. (12), (13) and (14), and comparison of the results with the thermogravimetric data is the process used to derive the preexponential factors and the activation energies of each of the three reactions plus the yield coefficients for the solid products. The kinetics parameters derived are shown in Table 1. Extraction of global kinetics from comparison to thermogravimetric experiments has been proven to be an efficient technique, as in [13]. These kinetic values obtained here are in good agreement when applied to other polyurethane thermogravimetric experiments [14] at a heating rate of $5^{\circ} \mathrm{C} / \mathrm{min}$. In addition, integration of the kinetics values for polyurethane given by Rogers and Ohlemiller [12] for air atmosphere results in a similar thermogravimetric curve as that presented here. However, since Rogers and Ohlemiller combined foam pyrolysis and foam oxidation in one reaction path, their kinetics were not suited for our model which has both the foam pyrolysis and the foam oxidation separately.

\subsection{Thermochemistry and Model Calibration}

Previous chemical studies of flexible polyurethane foam have mainly focused on pyrolysis degradation. As a consequence, there is little valid experimental information on the gas species for the oxidative reactions. This precludes the determination of reliable oxygen consumptions and consistent heats of reaction as applied to the polyurethane global reactions. However, Rogers and Ohlemiller [12] present a fine study of the thermochemistry of polyurethane foam. They experimentally determined the heat of pyrolysis and the heat of char oxidation, which are used in this model. Since the heat of foam oxidation that they reported includes the heat of pyrolysis, it is not suited for our kinetics scheme. Therefore calibration of the model results to the microgravity data is used to determine the values of these unknown parameters: oxygen consumptions for both foam and char oxidation reactions and heat of foam oxidation. These three parameters, however, are not independent if it is assumed that the heat release per mass of oxygen consumed is a constant value for the oxidation reactions [5]. Thus, Eq. (15) is imposed.

$\frac{\mathrm{v}_{\mathrm{O} 2, \mathrm{c}}}{\mathrm{v}_{\mathrm{O} 2, \mathrm{o}}}=\frac{\Delta \mathrm{h}_{\mathrm{c}}}{\Delta \mathrm{h}_{\mathrm{o}}}$

Given this assumption and using data from Rogers and Ohlemiller [12], the only two parameters left for calibration of the model are $\Delta \mathrm{h}_{0}$ and $\mathrm{v}_{\mathrm{O} 2, \mathrm{c}}$. The values determined after calibration are shown in Table 1. These values are of the same order as those derived by Ohlemiller et al. [5] with their onedimensional numerical model for smolder and in agreement too with the experimental estimations for the overall smolder process [12].

\section{Results}

The solid-temperature profiles obtained from the numerical model are shown in Fig. 3. The airflow velocities for these two cases are the same as for the microgravity experiments: $3 \mathrm{~mm} / \mathrm{s}$ and $5 \mathrm{~mm} / \mathrm{s}$. First it is observed that whereas the front in the $5 \mathrm{~mm} / \mathrm{s}$ case did propagate all through the porous sample, the front in the $3 \mathrm{~mm} / \mathrm{s}$ case was quenched at about half way. The smoldering peak temperature for the 3 $\mathrm{mm} / \mathrm{s}$ case is $480^{\circ} \mathrm{C}$ at $12 \mathrm{~cm}$, and the initial propagation velocity is around $0.11 \mathrm{~mm} / \mathrm{s}$ in agreement with the experiments. After $800 \mathrm{~s}$ the reaction has weaken and extinguishes. For the 5 $\mathrm{mm} / \mathrm{s}$ case, the smolder peak temperature corresponds to that of self-propagation and is $430^{\circ} \mathrm{C}$ with a velocity of $0.26 \mathrm{~mm} / \mathrm{s}$, in agreement with the experiments.

The examination of other variables (heat released per reaction, mass fractions, gas velocity, etc), not shown in this paper, allows for a more detailed analysis of the mechanism involved in smoldering. Examination of the mass fractions in the air flowing through the porous matrix shows that most of the oxygen in the bulk gas is consumed, as experimentally observed [1]. Analysis of the reaction-rates spatial profiles shows that the pyrolysis front is moving a few $\mathrm{mm}$ ahead of the foam oxidation front, in the region where oxygen is depleted. The char oxidation reaction is moving with the foam oxidation but a few $\mathrm{mm}$ behind it, in the region where there is sufficient char and oxygen to sustain the char oxidation.

A comparison of the model results with the experimental temperature profiles vs. time for different locations is shown in Fig. 4. In the experiments, the thermocouples measuring the temperature were placed in the center of the sample along the $x$-axis. In both cases, the faster temperature increase at $t=400 \mathrm{~s}$ is due to the effect of turning from low airflow during the ignition to the nominal airflow.

For the $3 \mathrm{~mm} / \mathrm{s}$ airflow case (Fig.4a) the peak temperature is due to a stronger and more localized char oxidation that ultimately quenches the smolder propagation. Since char oxidation has five times higher heat of reaction and oxygen consumption than foam oxidation, its influence in the smolder process is greater and leads to both significant temperatures rises and higher oxygen depletion. With limited oxygen supply (i.e. low inlet air velocities), in some locations char oxidation consumes most of the oxygen and produces a higher heat release rate than normal which causes the localized higher temperature-peak. The gas exiting the char oxidation region is depleted of oxygen and thus the foam oxidation reaction is oxygen-starved. This oxygen starvation, together with the higher heat-losses as the 
front is moving further from the hot igniter-assisted region, ultimately quench the smolder. This role of the char oxidation reaction is in accordance with the experimental interpretations of Bar-Ilan et al. [8], who state that at $3 \mathrm{~mm} / \mathrm{s}$ airflow, the char oxidation mechanism effectively quenched the smolder reaction leaving the last third of the sample unreacted. This quenching can be observed in Fig. $3 \mathrm{a}$ as the peak temperature gradually drops below smolder temperatures. This mechanism is effectively captured in the computational model although the predicted time and location of occurrence is not entirely accurate.

For the $5 \mathrm{~mm} / \mathrm{s}$ airflow case, Fig. 4b shows that selfpropagation of smolder is achieved and the model predicts the smolder velocity and the peak temperatures accurately. However, the model predicts more vigorous propagation at the end of the sample that in microgravity where the end-effect weakens the reaction at the last centimeters. It is observed that in the model, the igniter region reaches a lower temperature than in the experiments. It is the opinion of the authors that this increase in temperature in the experiments is due to localized char oxidation that raises the solid temperature to a range where secondary char-oxidation becomes significant. This secondary char-oxidation reaction is not implemented into the model and therefore the predicted peak-temperatures are lower near the igniter.

When directly comparing the temperature profiles with experiments, the model predicts the overall characteristics well at high temperatures, while the accuracy is lower at low temperatures and for the initial heating period. The present comparisons, despite the obvious inaccuracies, reproduce most of the important features of the process and this is a major improvement.

As seen in Fig. 4b, the solution for the temperature profiles contains some small pulsations that are generated by char oxidation. Mathematically, the pulsating behavior may be originated from a bifurcation of the solution [15], although no information on this issue has been reported for forward smoldering with char oxidation included. Numerical results of the smolder self-propagation velocity as a function of the inlet-air velocity are presented in Fig. 5. Comparison to experimentally measured smolder velocities allows concluding that the numerical model describes the experimental data qualitatively, and after calibration in a quantitative manner too. The model predicts no smolder-ignition for air velocities below $2.9 \mathrm{~mm} / \mathrm{s}$. For airflows close to $2.9 \mathrm{~mm} / \mathrm{s}$ but higher, the model predicts smolderignition but no self-propagation since the reaction quenches half way of the sample. For these cases, Fig. 5 reports the initial propagation velocity. It should be pointed out that the location of this no ignition limit is affected by the particular ignition and that the minimum airflow velocity predicted here is for the ignition protocol implemented in the experiments. Away from the no ignition limit, in the self-propagation regime, the smolder velocity is shown to be linear with the airflow as predicted for oxygen-limited smolder propagation $[1,2]$.

In actual fact, the inclusion of the external heat loss to the exterior makes a significant difference in the smolder characteristics. With no external heat loss, the char oxidation reaction dominates and engulfs the porous sample, resulting in solid temperatures up to $900^{\circ} \mathrm{C}$. This fact points out the possible application of the model to calculate the onset of flaming combustion in the gas phase and consequently predict the transition to flaming.

A major disagreement between the experiments and the numerical model is the total mass lost. While a typical smolder sample loses about half of its weight during smolder propagation in the core of the sample, the numerical model indicates weight losses up to $90 \%$. The main reason for this difference appears to be the inclusion of only one pyrolysis reaction in the attempt to model two consecutive reaction-paths, which causes the pyrolysis yield of char, $v_{c, p}$, to be significantly underestimated.

\section{Conclusions}

Results of one-dimensional transient simulations of forward smoldering were compared to the only available microgravity data. In order to do this, the already published core of the model was improved with the derivation and inclusion of polyurethane kinetics, the inclusion of external heat losses and the extraction (through calibration) of thermochemistry parameters of polyurethane. The optimization of these 10 parameters has been conducted using genetic algorithms The propagation velocity in microgravity has been used to calibrate the model and extract the heat of foam oxidation and the oxygen consumption for char oxidation of polyurethane foam. The model predicts the role of air velocity and char oxidation in accordance with experimental observations in microgravity. Comparison of the temperature profiles to experiments shows that while the accuracy is low at low temperature, the model predicts well the high temperatures and the propagation and extinction mechanisms.

The effect of inlet gas velocity was examined and a minimum airflow for ignition was identified. It is remarkable that this one-dimensional model with simplified kinetics is capable of predicting cases of smolder ignition with no self-propagation for airflows close to the minimum for ignition. The numerical model describes qualitatively well the experimental data and that after calibration good quantitative agreement is achieved.

The only two existing microgravity-experiments have been used here for comparison and calibration. Space-based experiments are difficult to conduct because of their elevated cost, and consequently the 
number of tests is generally limited, making numerical modeling a very important tool for the prediction of smoldering behavior in the absence of gravity. The model is used to extend microgravity data to different conditions and for better understanding of the controlling mechanisms of smolder for the purpose of fire safety, both in microgravity and normal gravity.

\section{Acknowledgements}

This work was supported by the National Aeronautics and Space Administration, under grant NAG3-2026. The authors would like to acknowledge the work and support during the development of this work of the NASA Glenn engineering team, and the thermogravimetric data files provided by Prof. Christopher Y.H. Chao and Prof. Jesús Ceamanos.

\section{References}

1. T.J. Ohlemiller, Progress Energy Combust. Sci. 11 (1985) 277-310.

2. G. Rein, A. Bar-Ilan, A.C. Fernandez-Pello, J.L. Ellzey, D.L. Urban, Western States Section Fall Meeting, Combust. Inst., Los Angeles, CA, 03F-38. (2003).

3. R. Friedman, Risk and Issues in Fire Safety on The Space Station, NASA TM 106403 (1993).

4. J. Oberg, Star-Crossed Orbits: Inside the U.S.Russian Space Alliance. McGraw-Hill, 2001.

5. T.J. Ohlemiller, J. Bellan, F.E. Rogers, Combust. Flame 36 (1979) 197-215.

6. C. Di Blasi, Combust. Sci. and Tech. 106 (1995) 103124.

7. S.V. Leach, G. Rein, J.L. Ellzey, O.A. Ezekoye, J.L. Torero, Combust. Flame 120 (3) (2000) 346-358.

8. A. Bar-Ilan, G. Rein, A.C. Fernandez-Pello, J.L. Torero, D.L. Urban, Experiment. Therm. Fluid Sci. (in press) (2004).

9. P.N. Brown, G.D. Byrne, A.C. Hindmarsh, SIAM J. Sci. Stat. Comp. 10 (1989) 1038-1051.

10. C.Y.H. Chao, J.H. Wang, J. Fire Sci. 19 (2001) 137155.

11. C.R. Houck, J.A. Joines, M.G. Kay. A genetic algorithm for function optimization: a Matlab implementation, NCSU-IE TR 95-09 (1995). http://www.ie.ncsu.edu/mirage/GAToolBox/gaot.

12. F.E. Rogers, T.J. Ohlemiller, J. Fire Flamm. 11 (1980) 32-44.

13. C. Branca, C. Di Blasi, A. Casu, V. Morone, C. Costa, Thermochimica Acta 399 (2003) 127-137.

14. R. Bilbao, J.F. Mastral, J. Ceamanos, M.E. Aldea, J. Analytic. Appl. Pyro. 37 (1996) 69-82.

15. A. Bayliss and B. Matkowsky, SIAM J. Appl. Math. 50 (2) (1990) 437-459. 


\begin{tabular}{lll}
\multicolumn{3}{c}{ Table 1. Values for the model parameters. } \\
\hline Ep & $200 \mathrm{~kJ} / \mathrm{mol}$ & Eq. (12) \\
$\mathrm{Ap}$ & $5 \mathrm{e} 15 \mathrm{l} / \mathrm{s}$ & Eq. (12) \\
$\mathrm{np}$ & 3 & Eq. (12) \\
$v_{\mathrm{c}, \mathrm{p}}$ & 0.05 & Eq. (12) \\
Eo & $155 \mathrm{~kJ} / \mathrm{mol}$ & Eq. (12) \\
Ao & $2 \mathrm{e} 12 \mathrm{1} / \mathrm{s}$ & Eq. (12) \\
$v_{\mathrm{c}, \mathrm{o}}$ & 0.4 & Eq. (12) \\
Ec & $185 \mathrm{~kJ} / \mathrm{mol}$ & Eq. (12) \\
$\mathrm{Ac}$ & $4 \mathrm{e} 13 \mathrm{1} / \mathrm{s}$ & Eq. (12) \\
$v_{\mathrm{a}, \mathrm{c}}$ & 0.3 & Eq. (12) \\
$\Delta \mathrm{hp}$ & $775 \mathrm{~J} / \mathrm{g}$ & {$[11]$} \\
$\Delta \mathrm{ho}$ & $-900 \mathrm{~J} / \mathrm{g}$ & Calibrated \\
$v_{\mathrm{O} 2, \mathrm{o}}$ & 0.12 & Eq. (15) \\
$\Delta \mathrm{hc}$ & $-4600 \mathrm{~J} / \mathrm{g}$ & {$[11]$} \\
$v_{\mathrm{O} 2, \mathrm{c}}$ & 0.62 & Calibrated \\
\hline
\end{tabular}




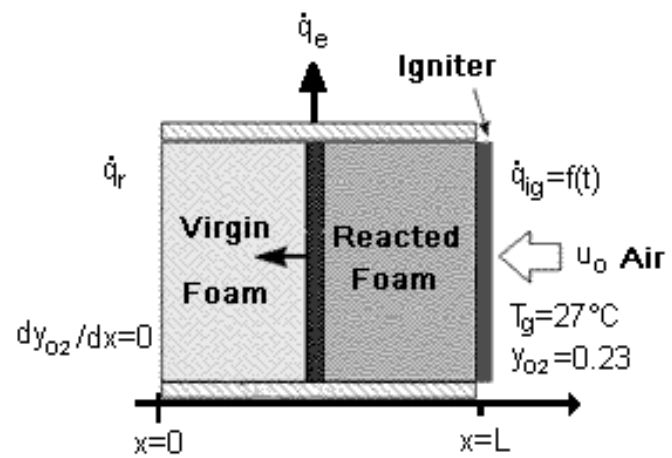

Fig. 1. Computational domain and boundary conditions.

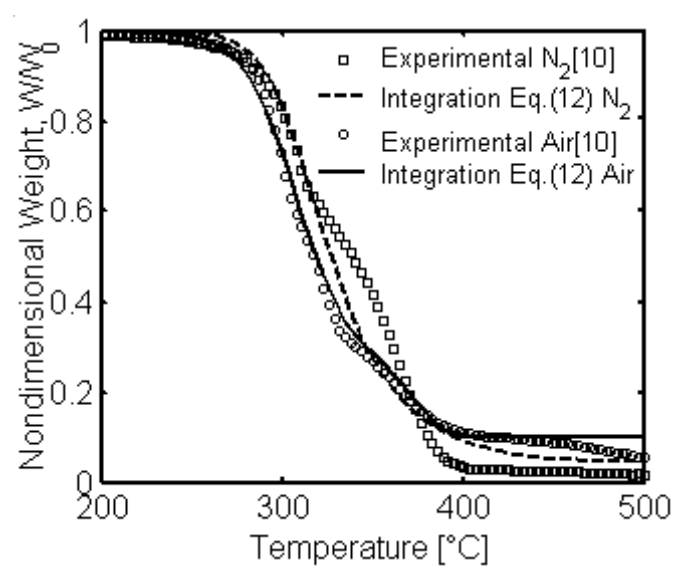

Fig. 2. Results of the numerical integration for inert and air atmospheres, and comparison to experiments at $10^{\circ} \mathrm{C} / \mathrm{min}$. 

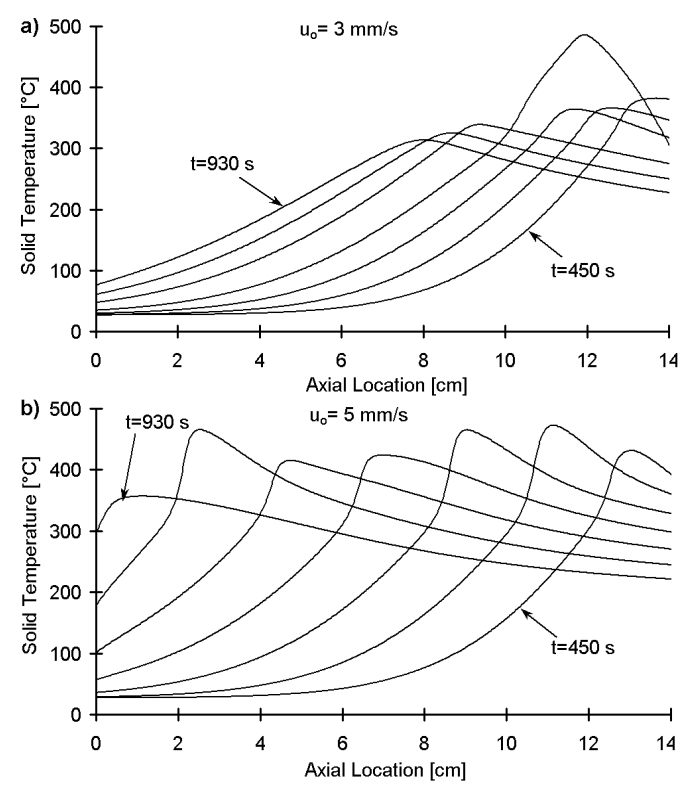

Fig. 3. Solid temperature vs. distance. Each line is a different time, starting at $410 \mathrm{~s}$ and in steps of $80 \mathrm{~s}$. Inlet velocity is a) $3 \mathrm{~mm} / \mathrm{s}$ and b) $5 \mathrm{~mm} / \mathrm{s}$. 

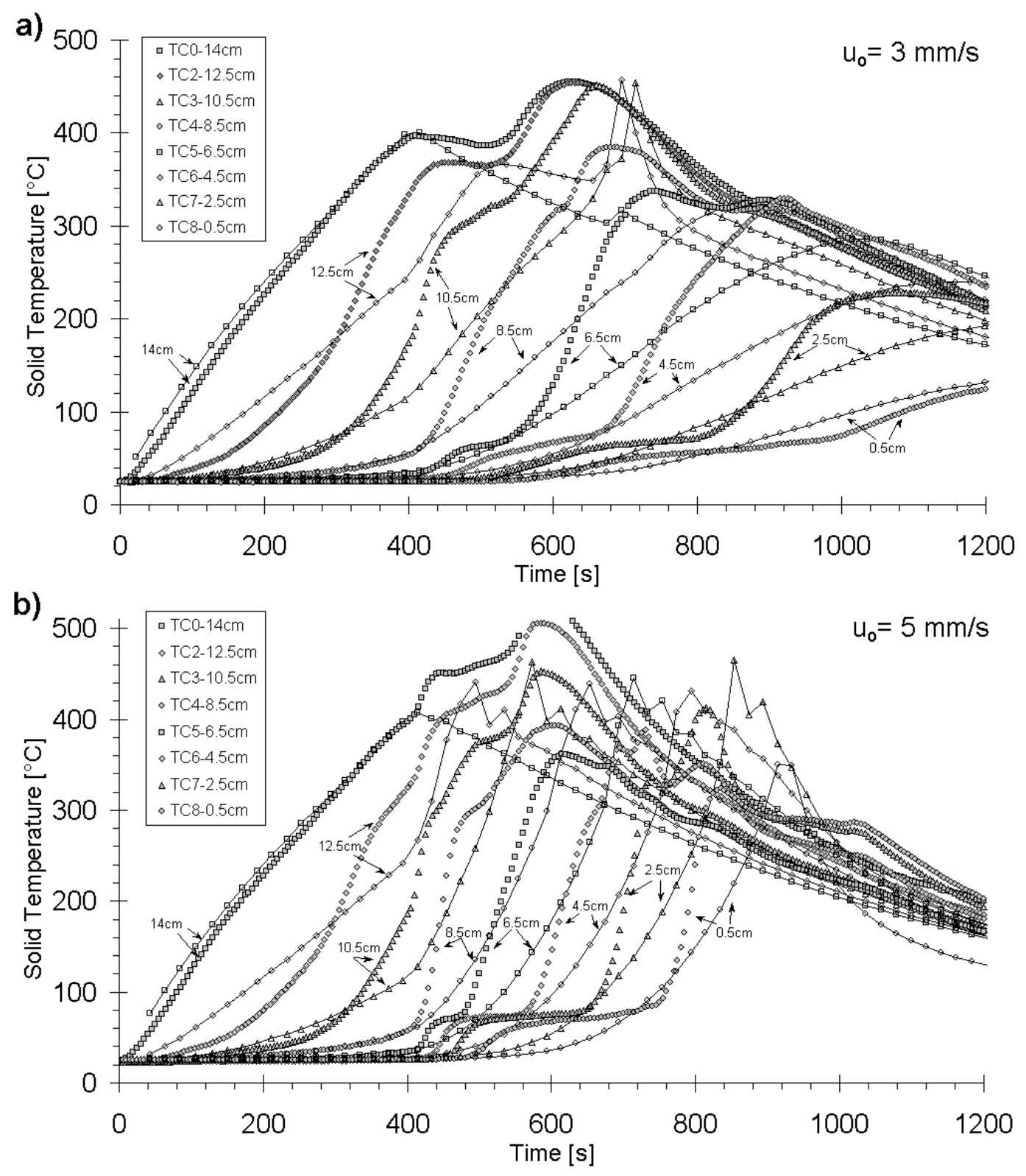

Fig. 4. Solid temperature vs. time at different locations. Comparison of model results (lines with empty symbols) and experimental measurements (filled symbols) for: a) $3 \mathrm{~mm} / \mathrm{s}$ and b) $5 \mathrm{~mm} / \mathrm{s}$ airflows. 


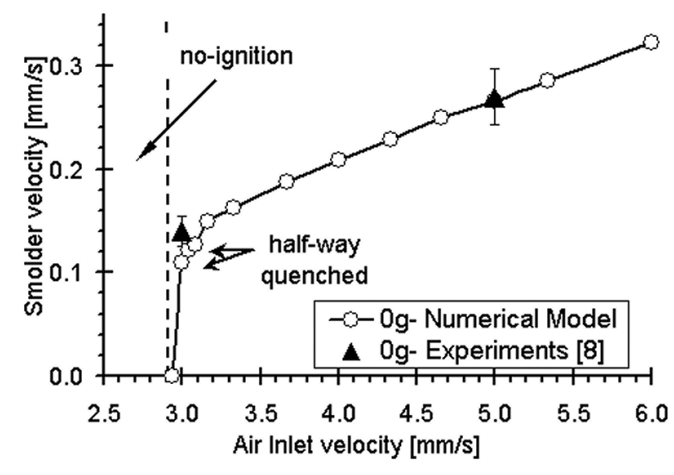

Fig. 5. Numerical results of smolder propagation velocity as a function of the inlet-air velocity, and comparison to experimental results. 